\title{
MULHERES EM AÇÃO E CATEGORIAS EM MOVIMENTO: A LUTA PELO TERRITÓRIO NA COMUNIDADE RIBEIRINHA DO PORTO DO CAPIM
}

\author{
Helena Tavares Gonçalves* \\ *Universidade Estadual de Campinas, Instituto de Filosofia e Ciências Humanas, Programa de Pós-Graduação \\ em Ciências Sociais, Campinas, SP, Brasil
}

\begin{abstract}
Resumo
Esse artigo procura levantar algumas reflexões em relação ao protagonismo da Associação de Mulheres do Porto do Capim na luta do território para fins de moradia. O debate envolve questões relacionadas ao direito à cidade através do agenciamento de noções de identidade, memória e patrimônio cultural, conduzida pelos moradores locais. Contudo, são as mulheres, organizadas politicamente, que estão à frente dos embates travados com o poder público. Procura-se mostrar em que medida um movimento de mulheres, ainda que não levante bandeiras feministas, é capaz de tencionar as estruturas do patriarcado ao negarem a possibilidade de remoção da comunidade e de propor formas alternativas de intervenções no território que garantam a manutenção do cotidiano das famílias, levando em conta a localização e mobilidade urbana, a instalação de serviços públicos de saúde e educação, de saneamento básico e qualificações dos espaços de uso coletivo do bairro.
\end{abstract}

Palavras-chave

Gênero; Território; Identidade; Patrimônio cultural; Memória. 


\title{
WOMEN IN ACTION AND CATEGORIES ON MOTION: THE STRUGGLE OVER LAND IN PORTO DO CAPIM RIVERSIDE COMMUNITY
}

\author{
Helena Tavares Gonçalves* \\ *Universidade Estadual de Campinas, Instituto de Filosofia e Ciências Humanas, Programa de Pós-Graduação \\ em Ciências Sociais, Campinas, SP, Brazil
}

\begin{abstract}
This article seeks to raise some considerations about protagonism of the Porto do Capim women's association in the struggle of the territory for housing purposes. The debate involves issues related to the right to the city, through the agency [agencement] of notions of identity, memory, and cultural heritage, carried out by [conducted] by local residents. Politically organized women are at the forefront of disputes with public power. It is considered as a movement women's, even if it does not identify as feminist, it is able to strain the structures of the patriarchal structure by denying the possibility of the removal of the community and proposing alternative forms of interventions in the territory that guarantee the conditions for the survival of families. The demands of women are directed towards the provision of public health services, the installation of public health and education services. They still require basic sanitation and improvements in collective use spaces in the neighbourhood, in addition to considering the urban mobility of the claimed territory.
\end{abstract}

Keywords

Gender; Territory; Identity; Heritage; Memory. 


\section{MULHERES EM AÇÃO E CATEGORIAS EM MOVIMENTO: A LUTA PELO TERRITÓRIO NA COMUNIDADE RIBEIRINHA DO PORTO DO CAPIM}

Helena Tavares Gonçalves

\section{Centro histórico em disputa}

A Comunidade do Porto do Capim, localizada nas Margens do Rio Sanhauá, no centro histórico da cidade de João Pessoa, sofre ameaça de remoção há pelo menos vinte anos, em função da execução de planos de revitalização propostos pelos poderes públicos que visam a requalificação desse espaço da cidade pensando exclusivamente nos usos turístico e de entretenimento. A primeira versão do projeto, elaborada em 1997, foi um dos produtos formulados a partir de um Convênio de Cooperação Internacional entre Brasil e Espanha ${ }^{1}$ e integrou a cidade de João Pessoa no Programa Patrimônio para o Desenvolvimento, financiado pela Agência Espanhola de Cooperação. O Programa vigorou entre os anos de 1987 e 2000, cujos detalhes estão presentes nos estudos realizados por Gonçalves (2014) e Scocuglia (2004; 2010). Essa proposta de intervenção, originalmente intitulada Projeto de Revitalização do Antigo Porto do Capim, foi reformulada diversas vezes ao longo dos anos, mas sempre mantendo a premissa da necessidade de remoção da população residente.

Foi nessa região que em 1920 houve a construção do Porto Internacional do Varadouro, o qual foi desativado já na década de 1940 (JOFFILY, 1983). Tanto a construção quanto a desativação do porto provocaram a vinda e fixação de famílias

1. Oficializado por meio do Decreto Estadual (Paraíba) nº. 12.239, de 24 de novembro de 1987. 
nessa região, em sua maioria trabalhadores responsáveis pelo carregamento das mercadorias contidas nos navios que ali atracavam, assim como famílias que viviam nas ilhas do estuário do rio Paraíba que, com a extinção do porto, viram a possibilidade de fixar moradia "em terra firme" (ASSAD, 2017). Importante ressaltar que essas pessoas já frequentavam aquela região, quando vinham comercializar nas feiras os produtos cultivados nas ilhas, como manga, coco, feijão verde e macaxeira. Isso revela que o processo de apropriação desse espaço da cidade pelas famílias ribeirinhas já acontecia por meio da atividade comercial devido a presença das feiras na região central de João Pessoa, mesmo antes da construção das casas de do uso habitacional.

As margens do Rio Sanhauá também foram palco de outros eventos, entre eles a chegada do colonizador, história que agrega um capital simbólico muito valorizado pelos órgãos oficiais de preservação do patrimônio cultural e que sustenta o mito de fundação da cidade, de modo que a região é frequentemente referenciada enquanto o berço de João Pessoa. No entanto, as fontes oficiais que relatam o processo de construção e transformação da cidade insistem na tentativa de apagar a narrativa histórica da presença da Comunidade Ribeirinha do Porto do Capim nessa região.

Um exemplo dessa tentativa de apagamento é o processo federal de tombamento do centro histórico ${ }^{2}$ que, em nenhum momento faz referência a presença desses moradores. Ao contrário, o estigma do abandono e da violência é o que procura qualificar as regiões do centro que necessitam de revitalização. Além disso, a necessidade de resgate do vínculo entre o rio e a cidade é reiterado constantemente, ignorando a relação que existe hoje entre os moradores atuais e o rio.

Curioso também o fato de que, apesar do tombamento estar referenciado no vínculo entre o rio e a cidade, o perímetro de proteção rigorosa exclui as margens do rio Sanhauá, deixando essa região na área de entorno ${ }^{3}$ do perímetro tombado (Figura 1).

Com frequência, planos de intervenção urbana têm ocasionado deslocamento de populações residentes e fomentado a chegada de novos grupos. No caso do Porto do Capim a ameaça de remoção se tornou mais incisiva quando, em 2012, a Superintendência do Iphan na Paraíba submeteu o Projeto Parque Ecológico

\footnotetext{
2. O tombamento é um instrumento técnico-jurídico cujo procedimentos estão regulamentados pelo Decreto Lei $n^{\circ}$ 25/1937, que incide na preservação de bens culturais de natureza material. O tombamento do centro histórico da cidade de João Pessoa é instruído pelo Processo Administrativo nº 1.501-T-02.

3. A área de tombamento do centro histórico divide-se em área de proteção rigorosa e área de entorno, que funciona como uma zona de amortecimento de impactos típicos do crescimento das cidades, onde se deverá salvaguardar a ambiência do sítio protegido, sendo que os efeitos do Decreto n² 25/1937 também incidem na área de entorno.
} 
Sanhauá ao financiamento do Programa de Aceleração do Crescimento (PAC) Cidades Históricas, o qual foi aprovado e posteriormente firmado um convênio com a prefeitura municipal para sua execução. A primeira fase do projeto consiste na remoção da parte da comunidade local $^{4}$ (aproximadamente 140 residências) para a implantação de um estacionamento com vaga para oitenta carros e a construção de um mirante.

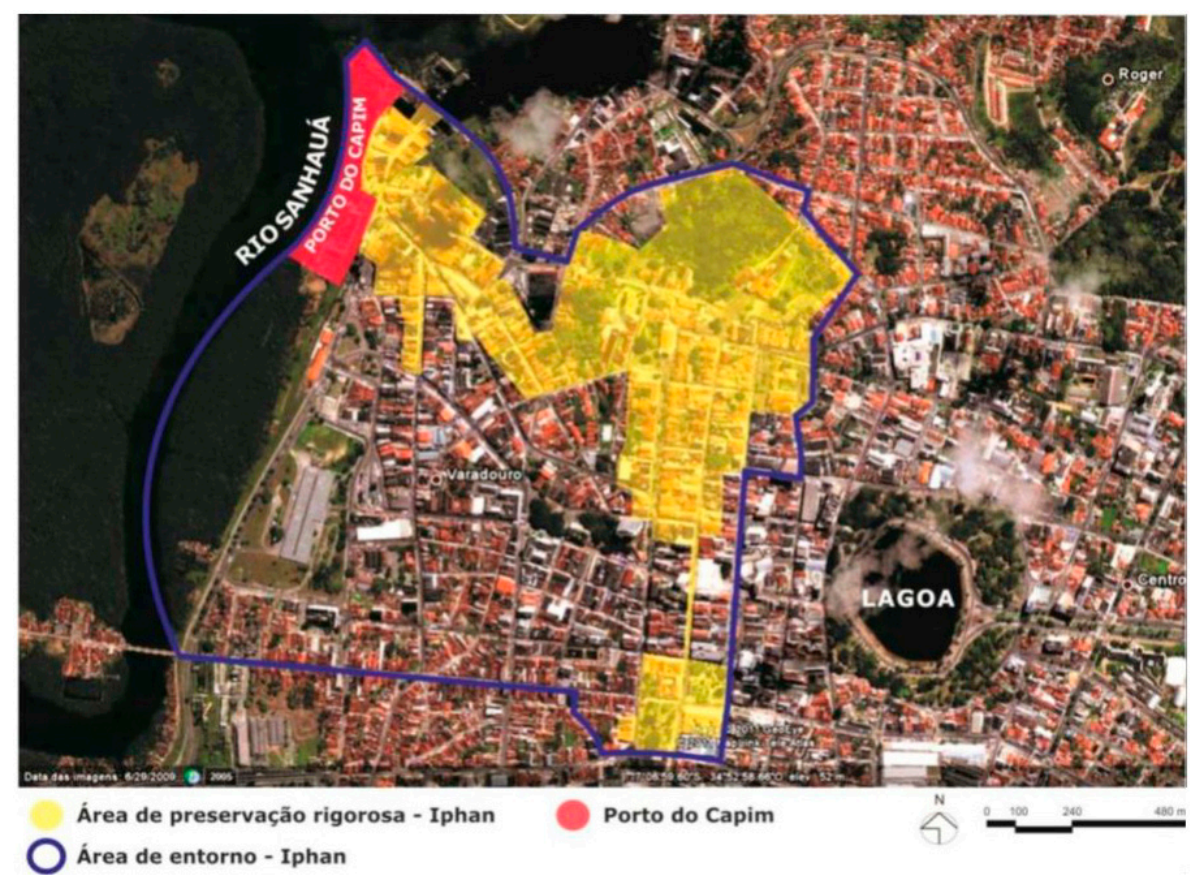

Figura 1. Perímetro de tombamento federal, entorno e destaque para o Porto do Capim Fonte: Acervo Iphan/PB, 2012.

Estudos apontam que, recorrentemente, os projetos de revitalização encaram as populações residentes enquanto um obstáculo à implementação de determinadas políticas públicas. Por consequência, os moradores locais ficam à margem dos projetos de requalificação urbana, que buscam a substituição de usos, usuários e proprietários para essas áreas. O "rumor" da remoção das populações residentes marca a presença do Estado na vida dessas pessoas, caracterizada pela ausência de diálogo e na imprecisão de informações sobre os planos de intervenção. A ameaça de ser expulso de seu território provoca a necessidade de organização e união das pessoas. Ao mesmo tempo, é necessário recorrer ao mesmo Estado para reivindicar formas de legitimar o uso do espaço.

4. Segundo dados da Secretaria Municipal de Saúde de João Pessoa, o território do Porto do Capim é composto por 420 residências. 
No caso do centro histórico de João Pessoa, os moradores do Porto de Capim recorreram - e recorrem - aos órgãos como Ministério Público Federal, Defensoria Pública da União e ao Centro de Referência de Direitos Humanos da Universidade Federal da Paraíba (UFPB) com objetivo de se fortalecer politicamente no processo de negociação com a Prefeitura Municipal e Instituto do Patrimônio Histórico e Artístico Nacional (Iphan). Nesse sentido, a "descida ao cotidiano" (DAS, 2007), como procedimento reflexivo, pode dar visibilidade às estratégias de permanência elaboradas pela população local na disputa pelo território.

Os dados etnográficos presentes nesse texto são resultado de pesquisas de campo realizadas a partir dos estudos de mestrado (2011 a 2013) $)^{5}$ e de doutorado (2017 a 2021) . O contato estabelecido por um extenso período permitiu o acompanhamento dos processos de formação das organizações políticas locais, possibilitou o estreitamento dos laços com alguns dos interlocutores a partir da construção de relações de confiança entre pesquisadora e moradores. A reflexão e produção de conhecimento sobre essa comunidade proporcionou também a contribuição na produção de documentos técnicos construídos coletivamente a partir de uma rede de apoio formada por diversos coletivos e organizações que se comprometem com a luta da Comunidade do Porto do Capim.

Se existe uma constante no Porto do Capim em relação às dinâmicas de formação de grupos de moradores organizados em movimento sociais em defesa da permanência, ela consiste no fato de sempre serem compostos por mulheres. Diante do fato, faz-se necessário pensar sobre quais são os fatores que mobilizam as mulheres a se tornarem as principais representantes da comunidade na disputa pelo direito de habitar o centro histórico da cidade?

As tentativas de legitimação de ocupação desse espaço, para fins de moradia, derivaram de um processo de formação e engajamento político que envolveu diversos agentes e agencias, onde as mulheres, organizadas em defesa de um interesse comum, passaram a operar com outras categorias identitárias que assumiram prioridade na conjuntura da luta por permanência. Nesse cenário, é importante observar como o território influencia na combinação e composição de categorias sociais (AUAD; SOUZA, 2016), ao mesmo tempo em que essas categorias implicam em percepções sobre esse mesmo território, gerando pontos de interconexão entre o espaço ocupado e os processos de construção de sentimentos de pertencimento identitário.

\footnotetext{
5. Programa de Mestrado Profissional em Preservação do Patrimônio Cultural do Instituto do Patrimônio Histórico e Artístico Nacional (Iphan).

6. Programa de Doutorado em Ciências Sociais da Universidade Estadual de Campinas (Unicamp).
} 
Tudo começou daqui do trapiche. O transporte começou do trapiche, a vida começou daí. Então o trapiche é a cabeça da comunidade, lá em baixo. Aí, essa área aqui que é onde botava as mercadorias, aqui já é o coração. Lá na Nassau já é os pés. A mãe maré eu desenho que ela tá assim ó, a cabeça lá do trapiche, aí vem pra cá o corpão dela, até chegar na Nassau. É uma grande mulher a mãe maré! Eu sou muito agradecida porque a mãe maré também é mãe dos meus filhos. (Entrevista realizada com Odaci de Oliveira Santos, em março de 2019 no Porto do Capim).

O território do Porto do Capim está dividido em quatro áreas: Frei Vital, Porto, Praça VX e Vila Nassau (Figura 2). Odaci, moradora da área do Porto, comerciante local, aposentada e integrante da Associação de Mulheres do Porto do Capim (AMPC), faz a leitura do território tendo como referência geográfica e simbólica a "Mãe Maré”, responsável pelos aspectos da reprodução e do cuidado da vida, tarefas culturalmente atribuídas às mulheres. Descrevendo-a como uma mulher deitada nas margens do rio com a frente do corpo virada para a comunidade, cumprindo a função de proteger aquelas pessoas, sendo, a Maré, também mãe das crianças do Porto.

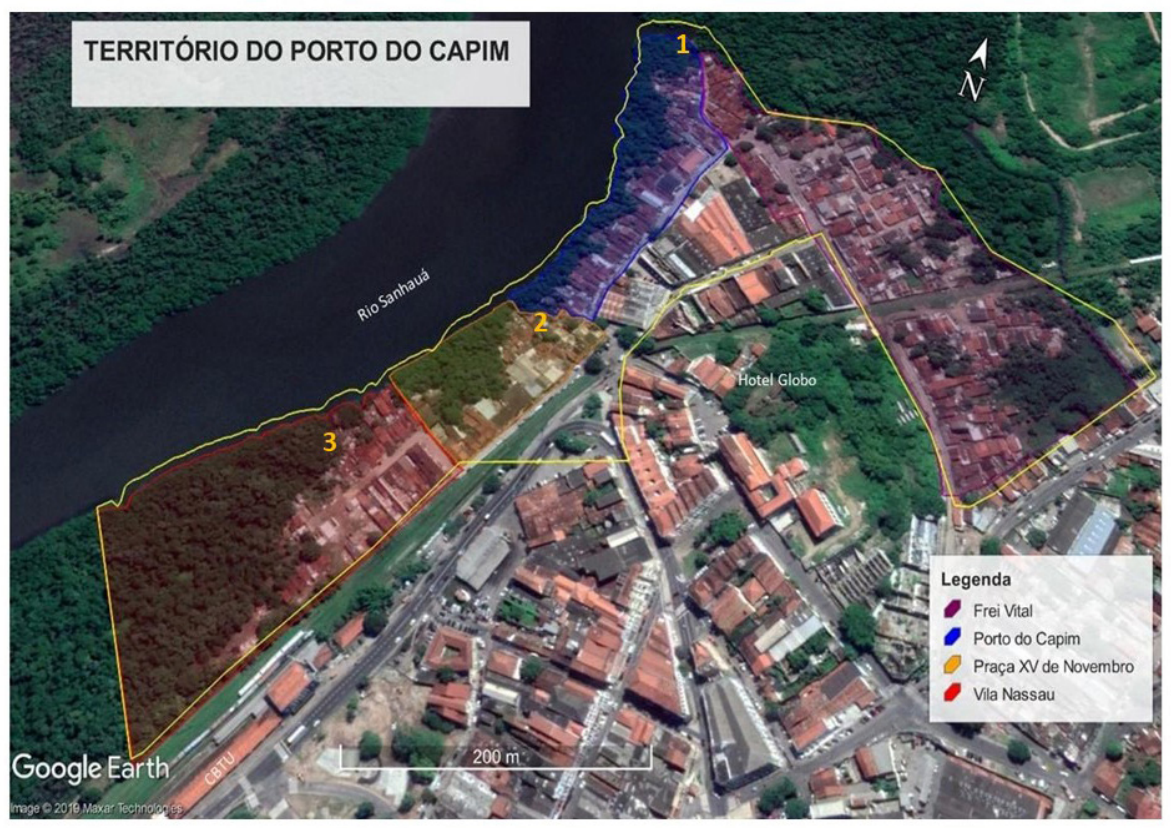

Figura 2. Perímetro de tombamento federal, entorno e destaque para o Porto do Capim Nota: 1. Cabeça; 2. Coração; 3. Pés.

Fonte: Proext Abrace o Porto do Capim, 2015 
A partir da descrição do território baseado na centralidade da Maré, é possível localizar indícios que auxiliam na compreensão do protagonismo das mulheres na luta pela permanência, por meio de uma chave de leitura relacionada aos aspectos da reprodução e do cuidado, tarefas socialmente atribuídas ao universo feminino. Mães garantem a existência das gerações futuras e as mulheres, de forma geral, são as responsáveis pelo cuidado tanto dos mais novos quanto dos mais velhos. A Maré, sendo uma grande mãe, protege, cuida, provê alimento e garante um ambiente seguro para os filhos do Porto ${ }^{7}$.

A leitura etnográfica desses espaços pode revelar as dinamicidades das formas de uso, dos movimentos e fluxos, os espaços de encontro, os pontos de comércio, as formas de interação de social. Pois, a partir dessas descrições é possível inferir como os espaços são ocupados e utilizados pela população local e em que medida essas vivencias incidem sobre a vida das mulheres.

O pequeno comércio local marca a atividade econômica do bairro, caracterizada tanto pela presença de estabelecimentos como mercadinho, lanchonete, oficina mecânica, cabelereiro, manicure, lan house, bares e restaurantes; como pela venda alimentos ${ }^{8}$ que os moradores comercializam em suas próprias residências. Muitas casas apresentam uma adaptação no espaço externo para o uso comercial, normalmente com uma varanda gradeada, onde, no seu interior há uma geladeira e prateleiras com mercadorias alimentícias. O comprador geralmente fica na calçada e a vendedora se dirige até rua para realizar a venda.

Constata-se que o sustento econômico de muitas famílias depende dos seus respectivos estabelecimentos localizados no bairro, muitas vezes, como extensão das próprias residências. Esse é o caso da Barraca de Cida, do Ibeji das Gêmeas, do carrinho de Wilma, da venda de Odaci, da mercearia de Nicinha, das mulheres que trabalham como manicures (também em suas residências) e daquelas que vendem salgadinhos e bolos sob encomenda.

A proximidade com o Rio Sanhauá possibilita a pesca artesanal, a coleta de mariscos e caranguejos, o cultivo de culturas, como macaxeira e feijão verde, realizada em ilhas fluviais próximas ao Porto do Capim. Os quintais das casas são fundamentais para a criação de caranguejo e galinhas. Em relação a espaços de convívio social e lazer, destaca-se o ponto de cultura comunitário, o largo do Quém Quém, o Trapiche, a mangueira de Zita, o prédio da Intendência da União, a Praça VX e a Praça da Resistência.

\footnotetext{
7. Categoria nativa utilizada pelos moradores quando se referem às gerações que já nasceram no Porto do Capim.

8. Carne, queijo, salgadinhos, din din (sorvete caseiro), bolos etc.
} 
A partir do mapeamento e da localização de uma diversidade de usos e formas de apropriação do espaço, o Porto do Capim pode ser qualificado através de suas pluralidades. Enquanto uma região que está no centro da capital paraibana, os trilhos de trem delimitam a fronteira com a região central da cidade, caracterizada pelo fluxo intenso de ônibus, carros, caminhões; marcada pela presença de prédios históricos, praças, instituições públicas, bancos, mercado central, feiras, terminal de ônibus intermunicipal, rodoviária, estação ferroviária e grande fluxo de pessoas transitando durante o dia. O Rio Sanhauá marca a divisão do espaço através de elementos naturais. A fauna e flora presentes no território tornam difícil a tarefa de admitir que estamos no centro da cidade. 0 rio, o mangue, a pesca, a coleta de marisco e caranguejo, os passeios nas croas ${ }^{9}$, os pássaros, os peixes, macacos, o silêncio. Esses elementos que são o oposto de uma ideia de urbanidade, também estão presentes no território do Porto do Capim (Figura 3).
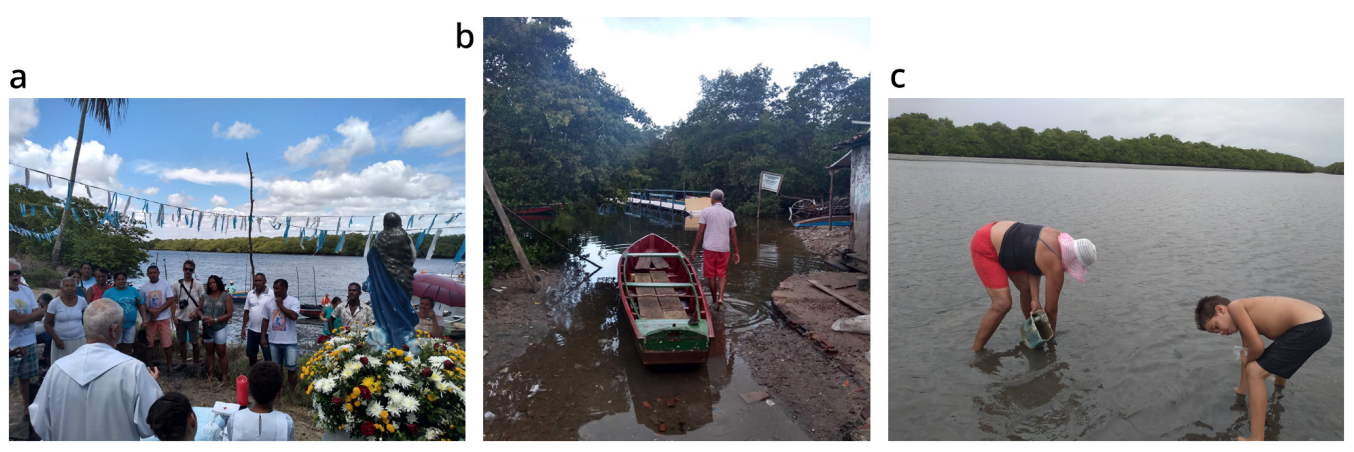

Figura 3. Usos do Rio

Legenda: a) Procissão fluvial em louvor a Nossa Senhora da Conceição; b) Trapiche de Seu Cosme; c) Dona Penha com seu bisneto na coleta de mariscos.

Fonte: Acervo pessoal da autora, 2018.

Em relação as sociabilidades presentes nesse cenário, existem alguns movimentos que se repetem cotidianamente. No início do dia as ruas costumam ficar vazias, não há grande fluxo de pessoas, com exceção das crianças que participam das atividades do ponto de cultura, elas costumam chegar ao local sozinhas ou acompanhadas dos irmãos maiores. A rua onde se encontram as madeireiras apresenta movimentação durante todo o horário comercial. No trapiche, a chegada dos pescadores depende do horário das marés. É depois do almoço que os moradores colocam as cadeiras na frente das casas e passam a tarde no espaço da rua. São idosos, donas de casa, pessoas que possuem comércio no Porto, adolescentes que não

9. Ilhas fluviais que aparecem e desaparecem de acordo com a cheia da maré. 
trabalham, pessoas que trabalham a noite ou que estão desempregadas. Ao anoitecer, aqueles que retornam do trabalho e as crianças que chegam da escola ocupam as ruas. As crianças com suas bicicletas, brincadeiras de pega-pega e futebol; os adultos sentam-se nos bares e nas calçadas para conversar, ouvir música e tomar cerveja. No entardecer também é possível observar as mulheres acompanhadas de seus filhos ou netos a caminho do culto em suas respectivas igrejas. Por volta da meia noite, as pessoas se recolhem para suas casas (Figura 4).

a

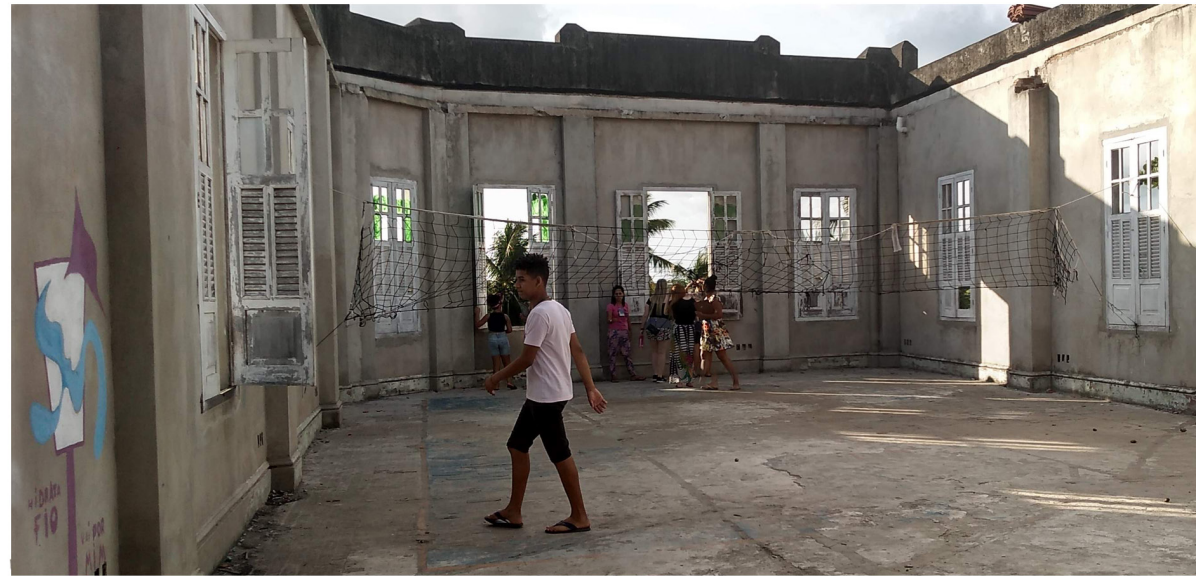

b

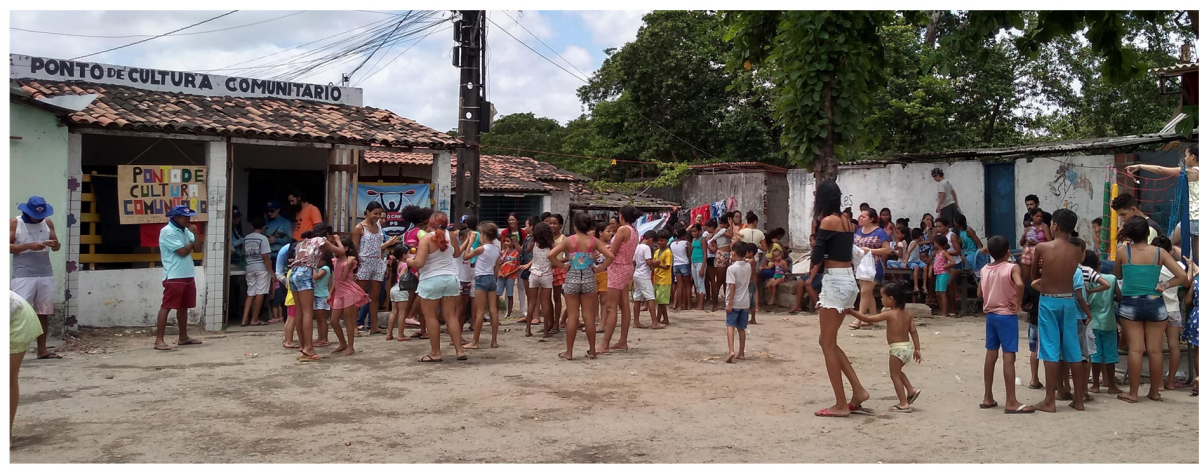

C

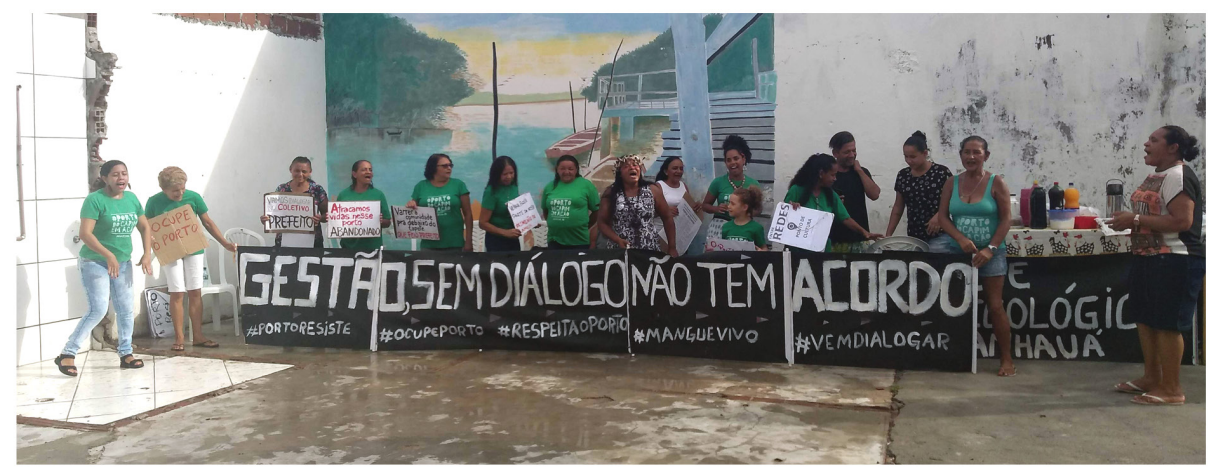

Figura 4. Usos da Rua

Legenda: a) Prédio da Intendência da União utilizado como quadra esportiva; b) Comemoração do Dia das Crianças no Ponto de Cultura Comunitário; c) Café da manhã com a imprensa na Praça da Resistência.

Fonte: Acervo pessoal da autora, 2018. 
Nessas dinâmicas, as relações sociais não só se desenvolvem, mas dependem também daquele território. Existe uma dimensão intangível das interações que alcança sua materialidade num espaço específico. Ou seja, o espaço é um elemento fundamental na configuração e na organização das relações sociais, que no caso do Porto do Capim mostra que esse território tem sido habitado por uma população marcada por laços de reciprocidade, interações socioambientais, cooperação econômica e uma relação de vizinhança estabelecida a partir de laços de parentesco.

Quando a população se organiza politicamente para reivindicar o direito ao território, o que está em jogo é a importância daquelas relações, tecidas naquele chão, que dizem respeito a uma forma específica de construir o cotidiano. Ao provocar mudanças, ressonâncias e Fricções (TSING, 2005) no campo do ordinário, os moradores locais precisam lidar com os desdobramentos ocasionados pelo tombamento do centro histórico, para que seja possível a reordenação de suas vidas cotidianas.

A questão analítica aqui problematizada é justamente a compreensão do protagonismo de mulheres na luta em defesa pelo território e quais as suas contribuições nas tentativas de reformulação dos planos de intervenção previstos para esse espaço da cidade. Para tanto, segue uma breve contextualização do processo de formação das três principais organizações locais: Comissão do Porto do Capim em Ação, Associação de Mulheres do Porto do Capim e Coletivo de Jovens Garças do Sanhauá.

Caranguejo que dorme acorda na corda: a trajetória dos movimentos sociais locais

As reuniões que resultaram na formação da Comissão do Porto do Capim em Ação passaram a ser organizadas em 2011, em parceria com uma organização não governamental ${ }^{10}$ que desenvolve ações de educação patrimonial com as crianças e adolescentes do Porto do Capim. Tendo em mente que, a primeira versão de um projeto de revitalização para a área do Porto do Capim, já prevendo a remoção dos habitantes data de 1997, podemos nos perguntar sobre o que significa viver, por mais de vinte anos, sob ameaça de remoção. As angústias e incertezas provocadas pelos rumores que enunciam a destruição do bairro é sentida e vivenciada de formas distintas pelos diferentes sujeitos que ali habitam. Como essa condição é vivenciada do ponto de vista das crianças, das mulheres, dos moradores mais antigos?

10. A Fundação Companhia da Terra, responsável pela execução dos Projetos Subindo a Ladeira e Rolezinho, atua na comunidade tendo como público alvo crianças e adolescente desde o ano de 2010. 
Ao realizar uma reflexão centrada na intersecção de gênero, violência e subjetividade, Veena Das (2007) aponta como as experiências do cotidiano fornecem elementos para a ativação de noções totalizadoras a partir de histórias individuais e coletivas. Nesse sentido, a formação da Comissão do Porto do Capim Ação proporcionou um espaço de troca de sensações e de informações que tornavam possível avaliar o teor do rumor das remoções. Nessa troca de experiências, somando-se a um trabalho de base e de formação política conduzido inicialmente por agentes externos (por meio de ONGs e Universidade), o grupo passa a cobrar do poder público esclarecimentos sobre o projeto de intervenção para a área e formas de evitar a destruição do bairro.

Os encontros da Comissão também proporcionaram um espaço para a socialização dos sentimentos provocados por todas as incertezas desencadeadas pela ausência de diálogo com o poder público. Os momentos de testemunho auxiliaram no processo de localizar o que aquelas pessoas não queriam perder, onde destacam as relações de vizinhança e parentesco, a importância de morar na região central da cidade, a preocupação com os quintais das casas, a constante reiteração do privilégio de viver numa região ainda não atingida por problemas de violência urbana, a apropriação da rua como um espaço de uso coletivo do qual depende a manutenção do cuidado das crianças, a Maré provedora de alimento, de entretenimento e de proteção.

Quando eu comecei na Comissão a gente tinha muito apoio, muita formação. Eu não falava como eu falo agora. Não conseguia ter segurança. Eu sabia o que eu queria, mas não tinha a segurança de falar. Entendeu? Aí, com a Comissão, com a Universidade, com as pessoas que vieram pra aqui, a gente se reunia e conversava sobre os nossos vínculos, o amor que eu tinha pelo local onde eu moro, aí eu consegui falar! (Entrevista concedida por Verônica, representante da Associação de Mulheres do Porto do Capim (AMPC), realizada em sua residência no Porto do Capim, em 12 de dezembro de 2018).

Essa primeira fase no processo de organização política as moradoras conquistaram voz, foram contempladas naquilo que era uma reivindicação constante pelas ruas da comunidade: "Nós queremos ser ouvidos". A organização das moradoras em Comissão proporcionou a divulgação da ameaça de remoção prevista pelo poder público, o que aproximou o contato com agentes universitários e coletivos culturais, que passaram a participar das reuniões semanais da Comissão. Além da organização de eventos festivos e comemorativos, o grupo conseguiu adentrar em espaços institucionais e incluir a discussão sobre a remoção em pautas específicas de secretarias municipais, passaram a cobrar respostas do poder público sobre o que exatamente estava previsto para a área. 
Os encontros da Comissão, por meio de uma produção coletiva de socialização de experiências, auxiliaram no processo de conectar a história de ocupação do território do Porto do Capim com uma narrativa mais ampla, que trata sobre a história de formação da cidade de João Pessoa. Essa semente de questionamento é um passo importante no desenvolvimento de ações futuras que foram elaboradas pelos movimentos sociais locais na luta pela legitimação do uso do território para fins de moradia.

A Associação de Mulheres do Porto do Capim (AMPC), é fundada em 2014. Segundo as mulheres que participaram do processo, havia a necessidade de criar um espaço de discussão sem a interferência de agentes externos. A partir da formação da associação de mulheres, as reuniões semanais, do que antes era o grupo da Comissão do Porto do Capim em Ação, deixaram de ser abertas. Passaram a participar dos encontros apenas as associadas. Segundo relato de algumas das integrantes, o grupo passou a buscar o protagonismo da luta através de uma organização interna que não necessitava, a todo momento, da mediação de agentes externos. Parcerias continuavam a ser estabelecidas, mas o momento de encontro da AMPC era apenas para moradoras.

É nesse momento a categoria de "comunidade tradicional" começa a aparecer na fala dos moradores. Alguns fatores específicos podem auxiliar na compreensão desse processo. O primeiro deles seria o reflexo das ações de formação política pelas quais passaram as mulheres que fizeram parte da Comissão do Porto do Capim em Ação. Isso porque quando essas mulheres se reuniam, era frequente a manifestação da importância que elas atribuíam aos aspectos de suas vidas cotidianas relacionadas ao território, o vínculo com o Rio, a pesca, ao mangue, às relações de vizinhança vinculadas as relações de parentesco. Os agentes externos auxiliaram no processo de compreender que aquele modo vida dizia respeito a um tipo específico de grupo social, que se tratava de uma comunidade ribeirinha.

Nesse contexto é desenvolvido o projeto "Museu do Patrimônio Vivo", financiado pela Secretaria de Cultura da Paraíba. Através da metodologia de pesquisa do Inventário Nacional de Referências Culturais (INRC), foram oferecidos cursos de formação para jovens moradores das localidades envolvidas, visando instrumentalizá-los para realizarem uma pesquisa acerca dos bens culturais imateriais de suas respectivas comunidades. Um dos resultados foi a publicação do "Catálogo de Bens Culturais Imateriais da Grande João Pessoa”. O inventário identificou e classificou os bens culturais de natureza imaterial a partir das categorias da política pública federal de patrimônio cultural. No Porto do Capim foram identificados os seguintes bens culturais: a) Formas de Expressão: Quadrilha Junina, Bloco Carnavalesco e Ala Ursa; b) Ofício e Modos de fazer: Pesca artesanal e pesca artesanal de marisco; 
c) Lugar: Trapiche, Rio Sanhauá e Território da Comunidade Porto do Capim; d) Celebração: Procissão de Nossa Senhora da Conceição.

Percebe-se que, através de várias frentes de trabalho, a estratégia de luta em defesa do território do Porto do Capim recebeu um investimento em se reconhecer e tornar público as referências culturais locais, atribuindo um sentido de tradicionalização ao cotidiano, o que desencadeou um processo de reconhecimento dos moradores enquanto patrimônio vivo do centro histórico, reivindicando que a história do Porto do Capim também faz parte da história da cidade, o que auxiliou no processo de auto reconhecimento dos moradores enquanto uma comunidade tradicional ribeirinha urbana.

Entre os anos de 2014 e 2017, diversas frentes de trabalho foram colocadas em movimento pela AMPC, em parceria com uma rede de apoio formada por agentes externos, destacando-se a importância de projetos de extensão universitária ${ }^{11}$. As parcerias resultaram na elaboração de documentos técnicos importantes como o relatório de violação de direitos humanos ${ }^{12}$, projetos de requalificação urbana construídos através de metodologias participativas ${ }^{13}$, abertura de inquérito civil público no Ministério Público Federal (MPF) ${ }^{14}$, conquista do reconhecimento enquanto comunidade tradicional por meio de relatório antropológico ${ }^{15}$ e inauguração do Ponto de Cultura Comunitário.

O processo de construção de laudos e contra-laudos, que atestam ou desaprovam a viabilidade da permanência dos moradores, revela que o modelo de planejamento urbano, (seja de habitação social, de requalificação, de revitalização, de distribuição de equipamentos públicos), não é uma decisão técnica. Trata-se de uma escolha política que precede a elaboração técnica de um projeto. Nesse sentido, a disputa pela permanência no Porto do Capim diz respeito à disputa sobre um

11. O Projeto Abrace o Porto do Capim contava com professores e alunos da Universidade Federal da Paraíba (UFPB) das áreas de arquitetura, história, geografia, direito, serviço social, teatro, dança, música e comunicação social. Foi contemplado pelo edital PROEXT 2015/2016 e classificado em primeiro lugar, a nível nacional, na categoria de Desenvolvimento Urbano.

12. O Centro de Referência de Direitos Humanos da Universidade Federal da Paraíba (UFPB), foi responsável pela elaboração do Relatório de Violação de Direitos Humanos no Porto do Capim, documento utilizado para embasar a denúncia que resultou na abertura de Inquérito Civil no Ministério Público Federal.

13. O projeto se desenvolveu entre os anos de 2015 e 2016, consistiu na residência técnica de estudantes de Arquitetura e Urbanismo para aplicação da Lei Federal nº 11.888/2008.

14. Ministério Público Federal. Procuradoria da República no estado da Paraíba. Inquérito Civil $\mathrm{n}^{\mathrm{0}}$ 1.24.000.001117/2015-16.

15. Parecer Técnico Antropológico $n^{\circ}$ 03/2015 do Ministério Público Federal da Superintendência da Paraíba. 
modelo de cidade, sobre quem tem o direito de viver, usufruir e fruir determinados espaços urbanos.

No fim do ano de 2016, aparece na cena comunitária o protagonismo de jovens moradoras na organização e gestão do Ponto de Cultura, resultado do esforço de mobilização conduzido por integrantes da AMPC para incluir outras gerações nos debates e ações comunitárias. Uma das ações coordenadas pelo Coletivo de Jovens Garças do Sanhauá é o Projeto de Turismo de Base Comunitária Vivenciando o Porto. O passeio contempla um circuito pelo bairro, passando pelos pontos de memória local, que contempla a visitação das antigas estruturas portuárias até os espaços de referências culturais que hoje são importantes para contar a história dos habitantes desse centro histórico, o que torna o passeio capaz de conectar a narrativa oficial de formação e de desenvolvimento da cidade, às histórias locais, das famílias e seus espaços de resistência.

Feita essa breve reconstrução dos processos históricos de formação dos três principais movimentos sociais locais, resta investigar por que são as mulheres os sujeitos políticos que protagonizam a luta em defesa do território. Na disputa em serem considerados ocupantes legítimos daquele espaço da cidade, moradores operam no agenciamento de noções de identidade, tradição e memória, utilizando-se de categorias mais abrangentes no contexto local (mais abrangente do que, por exemplo, a categoria mulheres), acionando as noções totalizadoras de tradicionalidade e de patrimônio, a partir das memórias coletivas e do processo histórico de ocupação daquele lugar. Porém, são as mulheres que ocupam os espaços de representação e negociação nas instâncias políticas, que reposicionam o debate sobre o projeto de cidade, questionando o modelo dos planos de intervenção previstos para a região do centro histórico. Fatos que nos colocam a pensar sobre as intersecções possíveis entre as questões de gênero, território e direito à cidade.

Embora a AMPC não questione as estruturas do patriarcado e nem busque a superação da desigualdade de direitos entre homens e mulheres, ao serem as protagonistas da luta em defesa do território e ao desempenharem uma atividade política/ativista importante e de destaque em sua comunidade, de que forma a autonomia conquistada por essas mulheres podem provocar ressonâncias em questões internas à comunidade, atravessadas pela questão de gênero?

Além da participação em movimentos sociais organizados, o protagonismo feminino se faz presente em projetos que estão relacionados à vivência cotidiana. As iniciativas femininas relacionam-se com demandas que se ligam às esferas da produção e da reprodução de suas condições de vida. Nesse sentido, a universidade e outras instituições que implementavam projetos na comunidade, encontravam nas mulheres suas principais interlocutoras: atentas à educação dos filhos, a 
dimensão do cuidado, o que justifica a reivindicação por projetos de melhoria de suas qualidades de vida, sempre pontuando a necessidade de instalação de equipamentos como posto de saúde, creche, parquinho nas praças, coleta de lixo regular, instalação de saneamento básico.

O movimento dessas mulheres revela que o protagonismo feminino vai além da associação direta entre mulheres e espaço doméstico. Outros fatores que atravessam a questão da moradia, dizem respeito ao questionamento em relação às formas de ocupação dos espaços a partir das funções socialmente atribuídas ao universo do feminino. Afinal, o direito à cidade ${ }^{16}$ (LEFEBVRE, 1991) também é marcado pela segregação de gênero e os projetos de habitação e planejamento urbano não são pensados a partir dessas diferenças. Diana Helene (2019), estabelece uma relação entre as desigualdades de gênero com a formação do capitalismo e das cidades, formatadas pela divisão social do trabalho, na qual "as funções destinadas às mulheres foram estruturadas como inferiores, não vistas como trabalho, e por essa razão, sem valor econômico” (HELENE, 2019, p. 4). Dessa forma, as noções capitalistas de público e privado, orientaram a organização urbana generificada, a partir da separação entre espaços produtivos e espaços reprodutivos. Por esse motivo, mesmo quando se tem onde morar, a localização no contexto urbano é fundamental, "devido ao fato de os espaços predominantemente voltados para habitação, marcados pelas atividades domésticas, constituírem-se como espaços nos quais as mulheres estão majoritária, cotidiana e constantemente presentes” (HELENE, 2019, p. 7).

A violação do direito à moradia e ao território do Porto do Capim, tem consequências específicas para as mulheres, que dependem dos espaços de uso coletivo e de ambientes seguros e conhecidos para desenvolver suas atividades comerciais, pelas tarefas ligadas ao cuidado dos filhos, irmãos, netos, afilhados, sobrinhos e pais. Essas atribuições, culturalmente encaradas como trabalho feminino, dependem do estabelecimento de redes de apoio e solidariedade que vem sendo tecidas no Porto do Capim há, pelo menos, setenta anos.

Reconhecer a ligação social e cultural da mulher com o espaço doméstico não pode significar um reforço da ideia de que lugar de mulher é na cozinha e de que o espaço público do mercado de trabalho, da política e das demais dimensões da vida é exclusivo dos homens. $\mathrm{O}$ importante é compreender que a garantia ao direito à moradia adequada às mulheres é fundamental para a realização de

16. Na cidade pensada para a manutenção do sistema capitalista, as desigualdades de classe são vividas e espacializadas nas formas de se planejar o espaço urbano. O direito à cidade diz respeito às reivindicações da classe trabalhadora em ocupar e existir nas cidades. 
suas atividades cotidianas e, inclusive, para a promoção de uma autonomia em todas as áreas da sua vida e para a efetivação de outros direitos (ROLNIK, 2011, p. 5).

Por meio do caso dos moradores do Porto do Capim, podemos localizar a coexistência e a interação de referenciais identitários diversos ${ }^{17}$, aqui a memória garante certa identificação dentro de um universo de lembranças possíveis, capaz de criar subjetividades compartilhadas. Debruçando-se sobre a questão das identidades Stuart Hall (1996; 2006; 2008) traz a imagem das identidades posicionadas que desencadeiam processos de identificação possíveis, num contexto de disputas permeadas por relações de poder que, através de articulações entre o global e o local, cria identidades híbridas, o que revela a capacidade dos sujeitos sociais em colocar em movimento categorias que por muitas vezes são encaradas de forma estanque.

Identidade não é algo que exista, transcendendo a lugar, tempo, cultura e história. As identidades culturais provem de alguma parte, têm história. Mas, como tudo que é histórico, sofrem transformação constante. Longe de fixas eternamente em algum passado essencializado, estão sujeitas ao contínuo jogo da história, da cultura e do poder. As identidades longe de estarem alicerçadas numa simples recuperação do passado, que espera para ser descoberto e que, quando o for, há de garantir nossa percepção de nós mesmos pela eternidade, são apenas os nomes que aplicamos as diferentes maneiras que nos posicionam, e pelas quais nos posicionamos, nas narrativas do passado (HALL, 1996, p. 69).

Nesse sentido, a categoria mulher aparece como uma característica de distinção interna nos processos de empoderamento político na luta da Comunidade do Porto do Capim, que, ainda que não apareça enquanto uma "bandeira de reivindicação" (como é o caso de outras categorias como Comunidade Tradicional e Patrimônio Vivo), é capaz de revelar como projetos de intervenção urbana, concebidos de forma extremamente genérica (a partir do olhar do homem, branco, neoliberal), podem ser mais ou menos violentos de acordo com a posição social de cada sujeito, atravessados por questões de classe, de gênero e de raça.

Esse caso mostra que a identidade posicionada é atravessada por outras categorias também ocupadas por essas mulheres, essa interseção revela o engajamento, podem dizer respeito a um lugar onde essas mulheres se organizam em defesa

17. Ribeirinhos, Patrimônio Vivo, Comunidade Tradicional e Mulheres. 
de um interesse comum, fazendo com que outras identidades sociais e relações, além do gênero, possam assumir prioridade em determinada conjuntura ou situação social.

A situação social de crise de sanitária e econômica provocada pela Pandemia do Coronavírus, atingiu profundamente as relações que possibilitavam a manutenção do cotidiano das famílias do Poto do Capim. Nessa conjuntura, o protagonismo feminino é acionado e, mais uma vez, são as mulheres que articulam as soluções e mediações possíveis para administrar os impactos da pandemia em âmbito local, as quais serão detalhadas nas próximas páginas.

\section{A centralidade da AMPC na gestão da crise provocada pela Covid 19}

Nos últimos anos, a prioridade dessas mulheres esteve relacionada à reivindicação ao direito de existir e viver em um determinado espaço da cidade. Recentemente, um evento crítico de âmbito global, impôs um novo desafio à comunidade, onde não só um "modo de vida" está em ameaça, mas a possibilidade de estar vivo devido os impactos provocados pela chegada do coronavírus. Nessa conjuntura, novamente são as mulheres que assumem a condução de ações para manejar os diversos impactos trazidos pela pandemia.

No início de 2020 o perigo de contágio de um vírus colocou a humanidade numa situação de vulnerabilidade nunca experenciada. Porém, é certo que a pandemia causa impacto de forma desigual nos diferentes grupos sociais, de acordo com as diferenças de raça, classe e gênero ${ }^{18}$.

Além da diferença de acesso à saúde pelas populações de baixa renda, a ausência de outros serviços básicos para a manutenção da qualidade de vida, como por exemplo acesso à saneamento básico e coleta de lixo, funcionam como vetores responsáveis pela maior disseminação da doença, somada a menor possibilidade de acesso a tratamento de saúde eficaz.

Tanto as medidas de isolamento social, quanto as de isolamento domiciliar (em caso de pessoas da família contaminadas) apresentam-se como soluções inviáveis para populações que dependem de uma renda que se faz no dia a dia através de serviços autônomos, temporários e informais. Essas mudanças dizem respeito não só a interrupção de circulação nas ruas, mas também alteração das dinâmicas internas à casa, como por exemplo, dormir em cômodos separados, utilizar banheiros individuais, manter janelas abertas para circulação de ar, lavar roupas de

18. Acerca de mais produções na área das ciências sociais em relação aos impactos sociais provocados pela pandemia ver GROSSI, M.; TONIOL, R. (org.). Cientistas Sociais e o Coronavírus. São Paulo: ANPOCS; Florianópolis: Tribo da Ilha, 2020. 
cama com mais frequência, além de estocar alimentos e produtos de higiene com intuito de circular menos nas ruas. Os moradores do Porto do Capim certamente não fazem parte do público ao qual se direciona esse conjunto de recomendações.

Num país marcado por profundas desigualdades sociais e ausência de políticas públicas que possibilitem o cumprimento das exigências sanitárias, articuladas à outras medidas de assistência social que integradas possam oferecer soluções razoáveis para o enfrentamento da pandemia, a disseminação do vírus vem nos mostrando a forma como os corpos são distintamente vulneráveis à infecção. Por outro lado, como apontam Nakamura e Silva (2020), é possível localizar redes de solidariedade e de iniciativas comunitárias que vem elaborando respostas às especificidades e necessidades das populações de baixa renda.

Tendo a plena consciência dos possíveis impactos da pandemia na vida daqueles que habitam o Porto do Capim, a AMPC teve - e tem - um papel central, promovendo estratégias articuladas e integradas para manejar os impactos da crise provocados pela pandemia.

O conjunto de ações organizam a frente de trabalho "O Porto contra o Vírus". Ao acionar uma rede de apoio com outros movimentos, a qual foi tecida ao longo dos anos anteriores em função da luta pela permanência no território, iniciativas da AMPC foram capazes de oferecer alternativas que puderam auxiliar na diminuição da necessidade de circulação de pessoas.

A ausência de dados oficiais sobre o perfil socioeconômico da população do Porto do Capim é mais um exemplo da tentativa de apagamento dessa população. Exceto informações do Censo de 2010 não há dados oficiais de quem são essas famílias. A falta de informação reflete na falta de acesso aos serviços públicos e a violação de direitos fundamentais estabelecidos na Constituição Federal de 1988.

Nesse contexto, a primeira ação da AMPC foi a elaboração de um questionário socioeconômico, com o objetivo de localizar quais seriam as famílias com o maior grau de vulnerabilidade, àquelas que apresentavam menor condição de manejar impactos ocasionados pela necessidade do isolamento social. Foram levantados dados como escolaridade ${ }^{19}$, renda $^{20}$ e trabalho ${ }^{21}$.

19. 52\% possuem ensino fundamental incompleto em contraposição aos 0,9\% que possuem ensino superior completo.

20. 61\% possuem renda inferior a um salário-mínimo e 53\% recebem algum tipo de benefício social, sendo que o Programa Bolsa Família contempla 80\% desse último grupo.

21. 73\% não possuem carteira de trabalho assinada e estão no setor informal, cuja atividades mais recorrentes são: reciclagem, serviços temporários nas madeireiras localizadas na comunidade, limpeza e faxina. 
A partir dos dados obtidos foram desenvolvidas diversas ações como: a garantia de alimentação através da distribuição de cestas básicas, entrega de marmitas e de materiais de higiene pessoal; estímulo a circulação de dinheiro na própria comunidade por meio de "vale-compra" a serem utilizados em comércios locais; auxílio emergencial para mulheres mães, cursos de formação direcionados aos cuidados e prevenção de contágio ao Corona Vírus e instalação de pias em diversos pontos do território ${ }^{22}$.

Na tentativa de cruzar alguns dados do questionário citado acima, constata-se que $87 \%$ das pessoas que responderam ao questionário são mulheres e dessas, $93 \%$ se consideram "chefes da família”. Apesar de não serem as que provém os recursos financeiros da casa, são elas as responsáveis pela gestão da economia doméstica.

\begin{abstract}
O questionário passa por essas categorias, né. De quem provem e de quem manda. De quem administra mesmo a família. Para além de colocar o dinheiro pra comprar as coisas, o homem ele é ausente, na grande maioria e o formulário mostra isso. Então a gente percebe que os homens estão a quem dessa situação de informação, de entender a importância de se comunicar entre redes, de se cadastrar também. Esse formulário não será útil só pra esse momento agora. A gente percebe que a mulher consegue pensar nessa questão de interseccionalidade de forma administrada, não colocando a frente quem provém, mas colocando a frente quem administra, quem de fato na realidade é a chefe de família. Ela consegue relacionar muito bem, apesar da situação de subalternidade, de estar numa posição de vulnerabilidade social, apesar de estar passando por dificuldade. Porque é a mãe que tá amamentando é a mãe que tá tendo que fazer o corre pra cuidar da casa e o homem que tá ausente. É a mãe que tá correndo atrás de viabilizar direitos básicos pra família. (Entrevista virtual realizada com Rossana Holanda, presidente da AMPC, em 24 de maio de 2020).
\end{abstract}

A pandemia continua em curso, no caso do Porto do Capim a existência de uma organização social que há anos vem enfrentando disputas relacionadas à permanência no território, atuando na melhoria e na intervenção dos espaços de uso coletivo, na gestão do ponto de cultura, na representação dos moradores nos espaços de negociação jurídicos, na publicização e divulgação da luta, na promoção de eventos comunitários, mostram a importância e necessidade das populações de

22. As ações da Campanha Porto contra o Vírus foram desenvolvidas em parcerias com outros movimentos e instituições como: Escola Frei Afonso, Casa Pequeno Davi, Espaço Mundo, General Store, Central Unificada de Favelas, Fundação Cia da Terra, Movimento de Médic@s Populares, Ministério Público Federal. 
baixa renda estarem organizadas em coletivos, geridos de forma autônoma através de redes de solidariedade tecidas por mulheres.

\section{Considerações finais}

Os debates feministas, tanto nas esferas dos movimentos sociais, quanto nas formas de análise teóricas, envolvem uma extensa literatura e uma diversidade de perspectivas e problematizações. Compreender esses processos históricos nos situa numa posição de admitir que eles se tratam de movimentos feministas, necessariamente no plural, que constroem suas percepções sobre a opressão baseadas em ideias e noções variadas sobre, por exemplo, mulher e patriarcado (TAVARES, 2016). Como afirma Butler (2003), a opressão das mulheres não possui uma forma singular, experenciada a partir de uma dominação genérica e universal do patriarcado, pois os mecanismos que estruturam opressões variam de acordo com contextos culturais concretos, onde incidem variadas formas de dominação.

O caso do Porto do Capim revela como determinadas categorias identitárias são agenciadas e colocadas em movimento. A noção de pertencimento é sempre construída pela mediação da memória, essa memória se constitui por um conjunto de lembranças que são acionadas de acordo com as necessidades de um grupo no tempo presente. São pontos de identificação no interior de uma narrativa, não são uma essência, mas sim um posicionamento, são passíveis de sofrer transformação.

Eu faço parte da Associação de Mulheres do Porto do Capim e sou moradora há 55 anos. Cinquenta e cinco anos, prefeito, não são cinquenta e cinco dias não, viu meu amor! Eu cheguei com cinco anos de idade, lá eu cresci, me tornei uma mulher, tive meus filhos, tenho meus netos. Lá a vida é maravilhosa. A natureza, a Maré nos torna desse jeito: mulheres fortes e homens fortes. Nossa Associação é de mulheres, mas a gente dá uma brechinha para os homens também! E aqui estou para adquirir os nossos direitos. Tem pessoas que estão lá há setenta anos, há oitenta anos. Como é que pode querer mudar a vida das pessoas assim? Nós gostamos de morar na beira da Maré, nossa Mãe Maré, e é lá que vamos ficar! Exigimos isso! Faz mais de vinte anos que esse monstro chamado prefeitura anda rondando a comunidade e tirando o sossego das pessoas. Estou gritando pelo meu direito porque eu quero envelhecer lá. (Odaci de Oliveira Santos. Fala realizada na Assembleia Legislativa da Paraíba em 11 de abril de 2019).

Odaci realizou essa fala numa audiência pública na Assembleia Legislativa da Paraíba. Nesse evento, todas as pessoas que realizaram intervenções foram moradoras locais, ocupando espaços de representação política predominantemente masculinos. Ao retornarem às suas casas, essas mulheres conquistam um novo status social, que as colocam em posição de destaque. 
Apesar do debate feminista, pautado na superação das desigualdades de gênero, não estar inserido nas reivindicações do Porto do Capim, a autonomia das mulheres no processo de luta nos faz pensar sobre os diferentes impactos causados pela ameaça de remoção. Já no caso da pandemia, essas pessoas se deparam com a necessidade de ficar em casa, quando nem sequer tem garantido o seu direito à moradia.

A manutenção do cotidiano das mulheres e das tarefas culturalmente atribuídas ao universo feminino (trabalho não pago), dependem de uma relação que está intimamente ligada ao uso dos espaços coletivos, onde se confundem e se misturam noções de público e privado. Nesse contexto, a rua é um espaço fundamental para a continuidade da reprodução do trabalho das mulheres, as quais organizam as tarefas por meio de laços de solidariedade e de parentesco espacialmente localizados.

A organização de movimentos sociais liderados por mulheres revela as possibilidades de transformação de realidades sociais específicas através de experiências concretas, muitas vezes à revelia da reivindicação de discursos feministas. As mulheres da AMPC, conquistaram um espaço representativo que vai da micropolítica no cotidiano às instâncias dos processos políticos e jurídicos. Assumem posição de destaque, garantindo sua autonomia, marcando um lugar de fala, espaço de poder, de capital político para dentro e para fora da dimensão da vida comunitária. Que, no fim das contas, são conquistas que fazem parte das lutas e reivindicações feministas.

\section{Referências}

AUAD, D.; SOUZA, R. Territórios e Feminismos: Gênero, classe e raça na vida das mulheres. In: ENCONTRO NACIONAL DE GEÓGRAFOS, 2016, São Luís do Maranhão. Anais do XVIII Encontro Nacional de Geógrafos. Maranhão: 2016.

ASSAD, P. Povo de ilha: Dinâmica territorial, identidade e tradição de conhecimentos no Porto do Capim. 2017. 135 f. Dissertação (Mestrado em Antropologia). - Centro de Ciências Aplicadas e Educação, Universidade Federal da Paraíba, 2017.

BUTLER, J. Problemas de gênero. Feminismo e subversão da Identidade. Rio de Janeiro: Civilização Brasileira, 2003.

DAS, V. Life and Words: Violence and the Descent into the Ordinary. Berkeley, CA: Univeristy of California Press, 2007.

GONÇALVES, H. O Porto e a Casa: Dinâmicas de transformação no uso dos espaços do centro histórico de João Pessoa (PB). 2014. 179 f. Dissertação (Mestrado em Preservação do Patrimônio Cultural) - Iphan, Rio de Janeiro, 2014. 
HALL, S. Identidade Cultural e Diáspora. Revista do Patrimônio, n. 24, Cidadania, p. 68-76, 1996.

A identidade cultural na pós-modernidade. Rio de Janeiro: DP\&A, 2006.

Da Diáspora: identidades e mediações culturais. Belo Horizonte: UFMG, 2008.

HELENE, D. Gênero e direito à cidade a partir da luta dos movimentos de moradia. Cadernos da Metrópole. São Paulo. v. 21, n. 46, p. 951-974, set/dez 2019.

JOFFILY, J. Porto Político. Rio de Janeiro: Civilização Brasileira, 1983.

MINISTÉRIO DA CULTURA. Instituto do Patrimônio Histórico e Artístico Nacional (Iphan). Processo de Tombamento n ${ }^{0}$ 1.501-T-02: "Centro Histórico de João Pessoa, Estado da Paraíba”. João Pessoa: IPHAN, 2002.

NAKAMURA, E.; SILVA, C. O contexto da pandemia de covid-19: desigualdades sociais, vulnerabilidade e caminhos possíveis. In: GROSSI, M.; TONIOL, R. (Org). Cientistas sociais e o coronavírus. São Paulo: ANPOCS; Florianópolis: Tribo Ilha, 2020, p. 160-165.

ROLNIK, R. Como fazer valer o direito das mulheres à moradia? São Paulo: Labcidade, FAUUSP, 2011.

SCOCUGLIA, J. Revitalização Urbana e (Re)Invenção do Centro Histórico da Cidade de João Pessoa. João Pessoa: Ed. Universitária da UFPB, 2004.

Imagens da Cidade: patrimonilização, cenários e práticas sociais. João Pessoa: Ed. Universitária da UFPB, 2010.

TAVARES, A. Movimento feminista em disputa: paradoxos entre discursos nacionais e práticas regionais acerca do tema da prostituição no Brasil. In: VALDIVIESO, M. (Org). Movimientos de mujeres y lucha feminista em America Latina y el Caribe. Buenos Aires: Clacso, 2016, p. 17-72.

TSING, A. Frictions. An Ethnography of Global Conection. Princeton: University Press, 2005. 


\section{Helena Tavares Gonçalves}

Com a graduação em antropologia pela Universidade Estadual de Campinas (Unicamp), tive a oportunidade de participar de projetos de extensão universitária junto ao Programa Comunidades Quilombolas, ocasião de primeiro contato com grupos e comunidades tradicionais. Ainda na graduação desenvolvi a pesquisa de iniciação científica Apropriações e Negociações do popular: A Festa de Iemanjá (BA), financiada pelo CNPq e premiada com Mérito Científico pela mesma instituição. Entre 2011 e 2014 realizei os estudos de mestrado no Programa de Preservação do Patrimônio Cultural, oferecido e com financiamento do Instituto de Patrimônio Histórico e Artístico Nacional (IPHAN), que teve como resultado a dissertação O Porto e a Casa: dinâmicas de transformação no uso dos espaços no centro histórico de João Pessoa, o que proporcionou o contato inicial com os moradores do Porto do Capim e minha participação junto aos movimentos sociais locais na luta contra a ameaça de remoção de seu território. Nessa ocasião optei por investigar as relações de conflito e negociação internas ao Iphan, em relação à remoção dos moradores do centro histórico em função de projetos de revitalização previstos para a área. Em 2014, atuei como servidora pública na Superintendência do Iphan no Amapá, ocupando o cargo de coordenação técnica da unidade, me envolvendo na gestão da política pública de patrimônio cultural em suas diversas vertentes. Após essa experiência, tive a oportunidade trabalhar em projeto da Unesco para o acompanhamento das políticas de salvaguarda do patrimônio imaterial na Superintendência do Iphan de São Paulo. Em 2017 ingressei no Programa 
de Doutorado em Ciências Sociais da Universidade Estadual de Campinas (Unicamp) e, contando com o financiamento da Coordenação de Aperfeiçoamento de Pessoal de Nível Superior (Capes/CNP), retomo o tema da dissertação e procuro investigar as formas de organização social e políticas dos moradores do Porto do Capim na luta pela legitimação do uso do espaço para fins de moradia. Esse artigo é resultado tanto da reflexão acadêmica proporcionada pelos cursos de pós-graduação e experiência profissional na área do patrimônio cultural, quanto da minha participação e atuação nos movimentos sociais locais, ligados à reivindicação dos direitos dessa população viver em seu território tradicional.

Email: helenatg@gmail.com

ORCID: 0000-0002-9303-0596

Submissão: 20 de dezembro de 2020.

Aprovação: 17 de julho de 2021.

Como citar: GONÇALVES, H. T. Mulheres em ação e categorias em movimento: a luta pelo território na Comunidade Ribeirinha do Porto do Capim. Revista brasileira de estudos urbanos e regionais. Dossiê Território, Gênero e Interseccionalidades. v. 23, E202125, 2021. DOI 10.22296/2317-1529.rbeur.202125

Artigo licenciado sob Licença Creative Commons CC BY 4.0.

https://creativecommons.org/licenses/by/4.o/deed.pt_BR 